\title{
REAKSI DEMAM PASCA PEMBERIAN KEKEBALAN AKTIF BUATAN VAKSIN DPT, HEPATITIS B DAN HAEMOPHILUS INFLUENZA TYPE B PADA BAYI BALITA
}

\author{
Danik Riawati $^{1}$, Titis Wahyuono ${ }^{2}$, Dewi Anggraini Kartika ${ }^{3}$ \\ 1,2Prodi DIII Teknologi Bank Darah, Akademi Teknologi Bank Darah Surakarta \\ ${ }^{3}$ Mahasiswa Prodi DIII Teknologi Bank Darah, Akademi Teknologi Bank Darah Surakarta \\ riawatidanik81@gmail.com ${ }^{1,}$ titis_wy@yahoo.co.id ${ }^{2}$, dewisari2404@gmail.com ${ }^{3}$
}

\begin{abstract}
Abstrak
Pendahuluan: Kekebalan aktif buatan dengan pemberian vaksinasi DPT Hepatitis B dan Haemophilus influenza type B dapat memberikan efek samping demam pada bayi balita dan perlu ditanggani sejak dini supaya cepat teratasi permasalahannya.

Tujuan: penelitian ini bertujuan untuk mengetahui gambaran reaksi demam pasca pemberian kekebalan aktif buatan vaksin DPT Hepatitis B dan Haemophilus influenza type B pada bayi balita.

Metode: Desain penelitian menggunakan observasional analitik. Tempat penelitian di Posyandu Melati Sabrang Lor pada bulan Desember 2019. Data diperoleh dari data primer dan sekunder. Populasi penelitian adalah semua balita yang pernah mendapatkan vaksin DPT Hepatitis B dan Haemophilus influenza type B di Posayndu Melati yaitu sebanyak 43 responden. Teknik pengambilan sampel accidental sampling. Analisis data univariat disajikan dalam pentuk distribusi frekuensi.

Hasil: Penelitian didapatkan bahwa sebagian besar usia bayi balita berusia $>36$ bulan yaitu sebanyak 31 (72,1\%), jenis kelamin laki-laki $25(58,1 \%)$ dan yang sebagian besar tidak mengalami reaksi demam pasca pemberian kekebalan aktif buatan vaksin DPT Hepatitis B dan Haemophilus influenza type B sebanyak 28 responden $(65,1 \%)$

Kesimpulan: Sebagian besar bayi balita tidak mengalami reaksi demam pasca pemberian kekebalan aktif buatan vaksin DPT Hepatitis B dan Haemophilus influenza tipe B.

Kata kunci: Reaksi demam, Vaksin DPT Hepatitis B vaccine and Haemophilus influenza type $B$, Bayi balita
\end{abstract}

\begin{abstract}
Background: Artificial immunity with the administration of DPT Hepatitis B and Haemophilus influenza type $B$ can give side effects of fever in infant infants and need to be considered early so that the problem quickly resolves.

Purpose: This research aims to determine the description of the post-fever reaction of active immune-made DPT Hepatitis B vaccine and Haemophilus influenza type B in infant infants.

Methods: Research design using analytic observational. Research venue at Posyandu Melati Sabrang Lor in December 2019. Data is obtained from primary and secondary data. The population of the research is all infants who have ever obtained the Hepatitis $B$ and Haemophilus influenza type B vaccine in Posayndu Melati, which is as much as 43 respondents. Accidental sampling techniques. Univariate data analysis is presented in frequency distribution. Result: Research gained that most of the infant's age is > 36 months, which is as much as 31 (72.1\%), male gender 25 (58.1\%) And most of which did not experience a post fever reaction of active immune-created DPT Hepatitis B vaccine and Haemophilus influenza type B as much as 28 respondents $(65.1 \%)$.

Conclusion: Most infant infants do not experience a post fever reaction of active immune-made the DPT Hepatitis B vaccine and Haemophilus influenza type B.
\end{abstract}


Keywords: Fever reactions, DPT Hepatitis B vaccine and Haemophilus influenza type B, infant toddler

\section{Pendahuluan}

Kasus Difteri tahun 2018 di Indonesia sebanyak 1368, kasus kematian sebanyak 29 kasus, dengan CFR sebesar 2,09\%. Menurut RISKESDAS tahun 2013 pengidap Hepatitis B mencapai 7,1\% menurut jenis kelamin laki-laki $8 \%$ dan perempuan $6,4 \%$ dan menurut lokasi tempat tinggal di perkotaan 6,3\% dan pedesaan 7,8\% (Kemenkes RI, 2019). Keberhasilan kesehatan ditentukan oleh sumber daya yang sehat, terampil, dan ahli. Salah satu upaya untuk menuju keberhasilan kesehatan dengan melakukan imunisasi, karena di Indonesia masih mempunyai dua beban dalam pembangunan kesehatan yaitu penyakit menular dan penyakit degeneratif (Kemenkes RI, 2013).

Imunisasi berasal dari kata imun, kebal atau resisten. Anak yang di imunisasi berarti diberikan kekebalan terhadap penyakit tertentu, karena imunisasi merupakan upaya untuk menimbulkan kekebalan tubuh seseorang secra aktif terhadap suatu penyakit, sehingga apabila suatau saat terpajan penyakit tersebut, maka tidak akan sakit atau hanya mengalami sakit ringan. Imunisasi juga ada kontraindikasi dan efek samping. Kontraindikasi merupakan keadaan yang kemungkinan dapat meningkatkan efek berbahaya yang tidak diinginkan sehingga vaksin tidak diberikan. Salah satu contoh kontraindikasi pemberian vaksin DPT HB Hib yaitu kejang atau gejala kelainan otak pada bayi baru lahir atau kelainan saraf serius (PPPTK, 2014). Efek samping vaksin DPT HB Hib antara lain reaksi lokal sementara seperti bengkak, nyeri dan kemerahan dan disertai demam (PPPTK, 2014). Hal tersebut menjadi salah satu penunjang keberhasilan imunisasi, karena dengan memberikan vaksisnasi maka akan memberikan imunitas yang efektif dengan menciptakan ambang mekanisme efektor imun yang adekuat dan sesuai beserta populasi sel memori yang dapat berkembang cepat pada kontak baru dengan antigen dan memberikan proteksi terhadap infeksi (Baratawidjaja K.G, Rengganis I, 2018).

Imunisasi DPT HB Hib menjadi program pemerintah yang termasuk dalam imunisasi dasar diberikan pada bayi usia 2, 3,4 bulan dengan interval pemberian 4 minggu dan imunisasi lanjutan pada balita usia 18 bulan yang diberikan hanya sekali. Vaksin DPT HB Hib digunakan untuk pencegahan terhadap difteri, tetanus, pertusis 
(batuk rejan), hepatitis B dan infeksi Hemophilus influenzae tipe b secara simultan. Vaksin ini diberikan dengan cara disuntik pada intramuskular antrerolateral paha atas dengan dosis 0,5 $\mathrm{ml}$ (PPPTK, 2014). Penelitian terdahulu yang pernah dilakukan oleh Sari P.M dkk, 2018 menyimpulkan bahwa hampir semua awitan gejala KIPI DPT terjadi pada hari pertama setelah imunisasi dan hampir semua gejala KIPI DPT menetap selama satu hari sampai seminggu setelh imunisasi. Studi pendahuluan yang pernah di lakukan penulis dengan melakukan wawancara pada beberapa ibu bayi balita di Posyandu Melati Mojosongo Jebres Surakarta, rata-rata pasca imunisasi DPT,HB, Hib bayi balita mengalami demam. Berdasarkan hal tersebut maka penulis tertarik mengambil judul "Respon Tubuh Balita Pasca Imunisasi DPT HB HIB".

\section{Tujuan}

Untuk mengetahui gambaran reaksi demam pasca pemberian kekebalan aktif buatan vaksin difteri pertusis tetanus hepatitis B dan Haemophilus influenza tipe B pada bayi balita.

\section{Metode}

Desain penelitian ini menggunakan observasional analitik. Tempat penelitian di Posyandu Melati Sabrang Lor pada bulan Desember 2019. data diperoleh dari data primer dan sekunder. Populasi penelitian ini adalah semua balita yang pernah mendapatkan vaksin DPT-HB-Hib di Posayndu Melati yaitu sebanyak 43 responden. Teknik pengambilan sampel accidental sampling. Analisis data univariat disajikan dalam pentuk distribusi frekuensi.

\section{Hasil}

Tabel 1 Distribusi frekuensi karakteristik responden

\begin{tabular}{ccr}
\hline Karakterstik & frekuensi & \% \\
\hline Umur & & \\
$<36$ bulan & 31 & 72,1 \\
$>60$ bulan & 12 & 27,9 \\
Jumlah & 43 & 100 \\
Jenis Kelamin & & \\
laki-laki & 25 & 58,1 \\
perempuan & 18 & 41,9 \\
Jumlah & 43 & 100 \\
\hline
\end{tabular}


Berdasarkan hasil diatas didapatkan bahwa sebagian besar usia bayi balita berusia $>36$ bulan sebanyak 31 responden $(72,1 \%)$ dan sebagian besar berjenis kelamin laki-laki sebanyak 25 responden $(58,1 \%)$.

Tabel 2 Distribusi frekuensi reaksi demam pasca imunisasi DPT, Hepatitis dan Haemophilus influenza tipe B

\begin{tabular}{|c|c|c|}
\hline Karakterstik & Frekuensi & $\%$ \\
\hline Demam & 15 & 34,9 \\
\hline tidak demam & 28 & 65,1 \\
\hline Jumlah & 43 & 100 \\
\hline
\end{tabular}
mengalami reaksi demam pasca pemberian kekebalan aktif buatan vaksin DPT Hepatitis B dan Haemophilus influenza tipe B yaitu sebanyak 28 responden $(65,1 \%)$.

\section{Pembahasan}

Hasil penelitian ini didapatkan bahwa sebagian besar usia bayi balita berusia $>36$ bulan yaitu sebanyak 31 responden $(72,1 \%)$, usia $>60$ bulan sebanyak 12 responden $(2,9 \%)$. Menurut teori bahwa pada saat bayi lahir sudah dapat memiliki kekebalan pasif, kekebalan ini didapatkan dari luar tubuh, seperti kekebalan pasif alami di dapat dari ibu melalui plesenta saat bayi masih didalam kandungan dan setelah lain kekebalan di peroleh dari pemberian air susu pertama (kolustrum). Hal ini juga didukung oleh penelitian Danik tahun 2016 di wilayah Mojosonggo Jebres Surakarta, menyimpulkan bahwa sebagian besar ibu menyususi memberikan ASI eksklusif yaitu sebanyak 35 responden (90\%) dan yang menyusui tidak eksklusif sebanyak 4 responden (4\%). Hal ini menunjukan bahwa ibu secara otomatis sudah memberikan kekebalan pasif pada anaknya.

Berdasarkan Jenis kelamin laki-laki 25 responden $(58,1 \%)$ dan perempuan sebanyak 18 responden $(41,9 \%)$. hal ini sesuai dengan teori bahwa sebelum pubertas sistem imun pada pria dan wanita adalah sama. Sistem imun berkembang tanpa pengaruh hormon seks. Adrogen yang dilepas pria bersifat imunosupresif, dilepas secara menetap selama masa dewasa dan tidak tidak berfluktuasi sampai usia lanju, sedangkan respon imun pada wanita terintegrasi dengan sistem endokrin yang tujuannya supaya janin dalam kandungan tidak ditolak selama hamil (Baratawidjaja K.G, Rengganis I, 2018). Bayi balita dan terutama bayi baru lahir sangat rentan terdapa penyakit, sehingga perlu meningkatkan daya tahan tubuhnya dengan cara memenuhu kebutuhan gizi bayi 
balita, karena kualitas tumbuh kembang anak dipengaruhi oleh dua faktor yaitu faktor dalam berupa ras/etnik/bangsa, keluarga/genetik/keturunan, umur dan jenis kelamin, faktor luar seperti gizi (saat ibu hamil), racun/zat kimia dan radiasi, kekurangan hormon tertentu, penyakit infeksi, sosial ekonomi yang kuarng, lingkungan pengasuhan, stimulasi/rangsangan (Kemenkes RI, 2010). Hal ini juga didukung oleh penelitian Danik tahun 2017 yang menyimpulkan bahwa pertumbuhan balita di Posyandu wilayah Mojosongo termasuk kategori status gizi baik sebanyak 35 responden (80,5\%), gizi kurang 7 responden $(17,1 \%)$, dan gizi lebih 1 responden $(2,4 \%)$.

Berdasarkan reaksi demam pasca pemberian kekebalan aktif buatan vaksin DPT Hepatitis B dan Haemophilus influenza type B yaitu tidak mengalami demam sebanyak 28 responden $(65,1 \%)$ dan yang mengalami demam sebanyak 15 (34,9\%). Efek samping vaksin DPT HB Hib antara lain reaksi lokal sementara seperti bengkak, nyeri dan kemerahan dan disertai demam (PPPTK, 2014). Hal tersebut menunjang keberhasilan imunisasi, karena pemberian vaksisnasi mempunyai tujuan untuk memberikan imunitas yang efektif dengan menciptakan ambang mekanisme efektor imun yang adekuat dan sesuai beserta populasi sel memori yang dapat berkembang cepat pada kontak baru dengan antigen dan memberikan proteksi terhadap infeksi (Baratawidjaja K.G, Rengganis I, 2018). Hasil penelitian ini menunjukan reaksi demam yang dialami bayi balita merupakan efek samping dalam pemberian vaksinansi dan hal tersebut dapat teratasi karena setiap selesai imunisasi ibu bayi balita di beri obat penurun panas yang digunakan untuk antisipasi apabila timbul demam. Penelitian ini didukung juga oleh hasil penelitian serologi oleh Rusmil et al, 2014 didapatkan bahwa anak yang diberi vaksin DPT-HB_Hib pada usia 18-24 bulan berdasarkan di ketahu bahwa Anti D 99,7\%, Anti T 100\%, HBSAg 99,5\%, sehingga dapat disimpulkan bahwa imunisasi DPT harus diberikan 3 kali dan tambahan pada usia 15-18 bulan untuk meningkatka titer anti bodi pada anak (Permenkes, 2017).

\section{Kesimpulan}

Sebagian besar bayi balita tidak mengalami reaksi demam pasca pemberian kekebalan aktif buatan vaksin DPT Hepatitis B dan Haemophilus influenza type B.

\section{Daftar Pustaka}

Danik Riawati, 2016. Karakteristik Ibu Menyususi Dalam Pemberian ASI. Jurnal Kebidanan Indonesia (Journal of Indonesia Midwifery) ISSN: 2086-5562Vol. 8, 
No.1,

Januari

2017.

https://jurnal.stikesmus.ac.id/index.php/JKebIn/article/view/163.Diakses tanggal 6 Desember 2019 jam 10.00 WIB.

Danik, 2017. Evaluasi Pertumbuhan Balita Berdasarkan Umur dan Berat Badan. Jurnal Kebidanan Indonesia (Journal of Indonesia Midwifery), ISSN 2086-5562 Vol.8 ,No.2, Juli 2017.https://jurnal.stikesmus.ac.id/index.php/JKebIn/article/view/18. Diakses tanggal 6 Desember 2019 jam 10.00 WIB.

Kemenkes RI, 2010. Pedoman Kader Seri Kesehatan Anak. Jakarta: Kemenkes RI.

Kemenkes RI, 2013. Peraturan Menteri Kesehatan No. 42 tahun 2013 Tentang Pedoman Penyelenggaraan Imunisasi.

Kemenkes RI 2019. Profil Kesehatan Indonesia Tahun 2018. https://www.kemkes.go.id/resources/download/pusdatin/profil-kesehatanindonesia/PROFIL_KESEHATAN_2018_1.pdf. Diakses tanggal 6 Desember 2019 jam 10.00 WIB.

PPPTK, 2014. Buku ajar Imunisasi. http://bppsdmk.kemkes.go.id/pusdiksdmk/wpcontent/uploads/2017/10/03Buku-Ajar-Imunisasi-06-10-2015-small.pdf. Diakses tanggal 6 Desember 2019 jam 10.00 WIB.

Permenkes, 2017. Penyelenggaraan Imunisasi. http://hukor.kemkes.go.id/uploads/produk_hukum/PMK_No._12_ttg_Penyeleng garaan Imunisasi .pdf.

Sari P.M dkk, 2018. Gambaran Kejadian Pasca Imunisasi Pada Anak Yang mendapatkan Imunisasi Difteri Pertusis dan Tetanus di Puskesmas Seberang Padang Kota Padang. Jurnal Kesehatan Anadalas Volumne 7 No.3. http://jurnal.fk.unand.ac.id 